\title{
Successful treatment of metaldehyde toxicosis with intravenous lipid emulsion in a dog
}

\section{Cristina Alexa Lelescu ${ }^{1}$, Cosmin Mureșan ${ }^{1}$, Aurel Muste ${ }^{1}$, Marian Aurel Taulescu ${ }^{2}$, Amalia Marina Neagu ${ }^{3}$, Andras Laszlo Nagy ${ }^{4}$}

\begin{abstract}
University of Agricultural Sciences and Veterinary Medicine, Faculty of Veterinary Medicine, ${ }^{1}$ Department of Surgery, ${ }^{2}$ Department of Pathology, ${ }^{3}$ Department of Pathophysiology,

${ }^{4}$ Department of Veterinary Toxicology, Cluj-Napoca, Romania
\end{abstract}

Received March 24, 2017

Accepted October 17, 2017

\begin{abstract}
The aim of the present report is to describe a novel successful treatment approach for metaldehyde poisoning in a dog: intravenous lipid emulsion therapy (ILE). A 2.5-month-old female Labrador Retriever was referred to the Emergency Department following deliberate ingestion of a metaldehyde-containing granular bait. Severe continuous tonic-clonic activity, muscle tremors, loss of consciousness, diffuse congestion of the oral mucosa, tachycardia, tachypnoea and nystagmus were observed upon admission. Additional intravenous administration of a $20 \%$ lipid emulsion resulted in normalization of the vital signs and complete neurological recovery. To the authors' knowledge, this is the first report describing ILE in the treatment of canine metaldehyde intoxication and the first description of a case of metaldehyde poisoning in a dog in Romania. Considering the severity of the neurological signs and the fact that no specific antidote is known, treatment can be significantly challenging to the veterinary practitioner. This finding should be included in metaldehyde poisoning therapy protocols, especially when severe clinical signs fail to respond to symptomatic treatment.
\end{abstract}

Poisoning, seizure, lipophilic, therapy, molluscicide, toxicity

Metaldehyde is a cyclic tetramer of acetaldehyde, widely used to control slugs and snails in agriculture and household gardening (Yas-Natan et al. 2007; Gupta 2012). The World Health Organisation classifies metaldehyde as a class II toxin, whereas the Unites States Environmental Protection Agency classifies it as a slightly toxic chemical (class II or III) (Gupta 2012).

Most frequently the exposure is oral, but the toxicant can also be absorbed from the skin and the lungs. After oral exposure, metaldehyde undergoes hydrolysis to acetaldehyde and it is further oxidized to acetic acid. Enterohepatic recycling of metaldehyde is also possible. Excretion is accomplished primarily through the urinary system and to a lesser extent through faeces, with a reported plasma half-life of $27 \mathrm{~h}$ (Gupta 2012). In dogs, the oral $\mathrm{LD}_{50}$ (median lethal dose) of metaldehyde is $100 \mathrm{mg} / \mathrm{kg}$ (Beasley 1999).

Metaldehyde acts primarily as a neurotoxicant; clinical signs include hyperpnoea, tachycardia, nystagmus, mydriasis, hypersalivation, ataxia, seizures, acidosis, hyperesthesia, diarrhoea, dehydration, hyperthermia and death (Booze and Oehme 1985; Beasley 1999; Puschner 2001).

There is no currently known antidote for metaldehyde toxicosis (Beasley 1999). The main objectives of the treatment include prevention of metaldehyde absorption, patient stabilization, management of the neurological signs and supportive care provision (Richardson et al. 2003).

In recent years, successful use of intravenous lipid emulsion (ILE) in various intoxications with lipid soluble compounds has been reported. Since metaldehyde is a lipid soluble toxin 
(Allen et al. 2004; Loftin 2012), the use of ILE as an adjuvant therapy in metaldehyde poisoning was investigated in a dog that failed to respond to symptomatic treatment.

\section{Case history}

A 2.5-month-old female Labrador Retriever, weighing $4.5 \mathrm{~kg}$ was referred to the Emergency Department for continuous generalized seizures following accidental ingestion of an unknown quantity of metaldehyde. The owners surprised the dog while she was eating from a bag of $100 \mathrm{~g}$ Optimol (40 g/ $\mathrm{kg}$ metaldehyde). Within an hour, the puppy started vomiting and actively seizing. Activated charcoal and diazepam were administered unsuccessfully at the local veterinarian.

The patient arrived within two hours after ingesting the toxicant. The initial physical examination revealed: continous generalized seizures, loss of consciousness, bilateral nystagmus, tachypnoea $(73 / \mathrm{min})$, tachycardia $(195 / \mathrm{min})$, hyperthermia $\left(40.1{ }^{\circ} \mathrm{C}\right)$ and diffuse congestion of the oral mucosa. A complete blood cell count revealed a haematocrit of $29.26 \%$, eosinopaenia $\left(0.04 \times 10^{9} / 1\right)$ and mild regenerative normocytic anaemia $\left(4.29 \times 10^{12} / 1\right)$. Blood electrolyte evaluation detected hypokalaemia $(3.91 \mathrm{mmol} / \mathrm{l})$, while sodium and chloride were within reference intervals. Later, diarrhoea was followed by melena and, subsequently, a bluish green content in the patient's faeces was noticed.

In order to manage the seizures, $1 \mathrm{mg} / \mathrm{kg}$ diazepam (Diazepam $5 \mathrm{mg} / \mathrm{ml}$, Terapia S.A., Cluj-Napoca, Romania) and $10 \mathrm{mg} / \mathrm{kg}$ phenobarbital (Fenobarbital Zentiva $100 \mathrm{mg} / \mathrm{ml}$, S.C. Zentiva S.A., Bucuresti, Romania) were administered intramusculary (IM), without satisfying results. Fifty $\mathrm{ml} / \mathrm{kg}$ Lactated Ringer's solution (LRS) (Solutie Ringer Lactat, B. Braun Melsungen AG, Melsungen, Germany) and $100 \mathrm{mg} / \mathrm{kg}$ calcium borogluconate (Borogluconat de calciu $38 \mathrm{~g} / 100 \mathrm{ml}$, ROMVAC Company S.A., Romania) were administered intravenously. Then, $1.1 \mathrm{mg} / \mathrm{kg}$ carbazochrome sodium sulphonate (Adrenostazin, Terapia S.A., Cluj-Napoca, Romania) and $1 \mathrm{mg} / \mathrm{kg}$ pantoprazole (Pantoprazol Teva $40 \mathrm{mg}$, TEVA Pharmaceutical Works Private Limited Company, Gödöllö, Hungary) were administered intravenously in order to cease the gastrointestinal bleeding and to aid the healing process of the gastric mucosa. Additionally, a continuous rate infusion (CRI) of propofol (Propofol-Lipuro $10 \mathrm{mg} / \mathrm{ml}$, B. Braun Melsungen AG, Melsungen, Germany) was initiated and maintained at a rate of $0.3 \mathrm{mg} / \mathrm{kg} / \mathrm{min}$. Despite the multiple doses of phenobarbital, diazepam and butorphanol (Butomidor $10 \mathrm{mg} / \mathrm{ml}$, Richterpharma AG, Wells, Austria) that were administered in addition to propofol CRI over a period of $8 \mathrm{~h}$, no significant improvement was seen; only a minor decrease of the neurological symptoms and short periods of normal pulse and respiratory rate were noticed after propofol administration. Nevertheless, the tonic-clonic activity was present during the entire period. Subsequently, a 20\% lipid emulsion (Lipofundin MCT/LCT 20\%, B. Braun Melsungen AG, Melsungen, Germany) was administered through a peripheral catheter as a bolus of $4 \mathrm{ml} / \mathrm{kg}$ over $15 \mathrm{~min}$, followed by a CRI of $0.25 \mathrm{ml} / \mathrm{kg} / \mathrm{min}$ over $60 \mathrm{~min}$. One hour after starting ILE therapy, pulse and respiratory rate had a tendency to normalize and tonic-clonic activity was abolished.

Serum biochemistry lipid profile was performed $6 \mathrm{~h}$ after ILE infusion. The serum sample appeared markedly turbid (creamy), which corresponds to a lipaemic index of $>120$. Lipid profile revealed markedly elevated levels of total cholesterol $(41.99 \mathrm{mmol} / \mathrm{l})$, triglycerides ( $158.9 \mathrm{mmol} / \mathrm{l})$ and total lipids $(4009.7 \mathrm{mg} / \mathrm{dl})$.

Further supportive care was provided by LRS infusion $(5 \mathrm{ml} / \mathrm{kg} / \mathrm{h}), 10 \mathrm{ml} / \mathrm{kg}$ aminoplasmal (Aminoplasmal 10\%, B. Braun Melsungen AG, Melsungen, Germany), $1 \mathrm{mg} / \mathrm{kg}$ pantoprazole, $2 \times 1 / 2$ tablet $\mathrm{S}$-adenosylmethionine/silybine (Denamarin $425 \mathrm{mg}$, Bioiberica S.A., Barcelona, Spain) administration. The patient's increased appetite allowed a gradual transition to oral feeding. Forty-eight hours later, a decrease in serum 
triglycerides $(9.47 \mathrm{mmol} / \mathrm{l})$, total cholesterol $(8.8 \mathrm{mmol} / \mathrm{l})$ and total lipids $(607.7 \mathrm{mg} / \mathrm{dl})$ was detected. An increased liver enzyme activity and high levels of creatine kinase were noticed (Table 1). A complete blood cell count showed a haematocrit of $29.84 \%$ and mild regenerative anaemia $\left(4.41 \times 10^{12} / 1\right)$.

At discharge, further treatment with pantoprazole $(1 \mathrm{mg} / \mathrm{kg} \mathrm{q} 12 \mathrm{~h}$, per os) and S-adenosylmethionine/silybine ( $425 \mathrm{mg} /$ tablet, $2 \times 1 / 2$ tablet, per os) was recommended for 10 and 30 days, respectively. The patient was discharged without any neurological abnormalities. Follow-up at 2 weeks revealed a clinically healthy patient, and serum biochemistry showed slightly increased levels of liver enzyme activity (Table 1).

Table 1. Haematological and serum biochemical values after intravenous lipid emulsion therapy.

\begin{tabular}{lccc}
\hline Analyte & 6 h post therapy & 48 h post therapy & Reference interval \\
\hline Triglycerides, mmol/1 & 158.9 & 9.47 & $<18.74$ \\
Total cholesterol, mmol/1 & 41.99 & 8.8 & $3.5-7.2$ \\
Total lipids, mg/dl & 4009.7 & 607.6 & $500-700$ \\
Blood urea nitrogen, mmol/l & - & 8.67 & $2.9-10$ \\
Creatinine, $\mu$ mol/l & - & 45.08 & $44-150$ \\
Aspartate aminotransferase, $\mu \mathrm{kat} / 1$ & - & 0.527 & $0.22-0.25$ \\
Alanine aminotransferase, $\mu \mathrm{kat} / 1$ & - & 0.84 & $<0.68$ \\
Gamma-glutamyltransferase, $\mu \mathrm{kat} / 1$ & - & 0.26 & $0.01-0.16$ \\
Alkaline phosphatase, $\mu \mathrm{kat} / 1$ & - & 3.42 & $0.01-1.93$ \\
Creatine kinase, $\mu \mathrm{kat} / \mathrm{l}$ & - & 1.27 & $0.88-6.25$ \\
Lactate dehydrogenase, $\mu \mathrm{kat} / 1$ & - & 6.13 & $0-3.93$ \\
Glucose, $\mathrm{mmol} / \mathrm{l}$ & - & 16.73 & $4.2-6.6$ \\
Amylase, $\mu \mathrm{kat} / \mathrm{l}$ & - & 0.32 & $3.84-18.07$ \\
Total bilirubin, $\mu \mathrm{mol} / \mathrm{l}$ & - & 0.32 & $0-5.1$ \\
Lipase, $\mu \mathrm{kat} / \mathrm{l}$ & - & 151.8 & $0.13-0.7$ \\
Sodium, mmol/1 & - & 4.36 & $142-152$ \\
Potassium, mmol/1 & - & 123.2 & $3.9-5.1$ \\
Chloride, mmol/1 & - & 0.29 & $110-124$ \\
Haematocrit & - & 4.41 & $0.37-0.55$ \\
Red blood cell count, $10^{12} / 1$ & - & $4.95-7.87$ \\
\hline
\end{tabular}

\section{Discussion}

Despite the wide utilization of metaldehyde-containing baits in Europe, no previous reports on metaldehyde toxicity in dogs were described in our country, probably due to lack of extensive use in this area. There are numerous reports on metaldehyde poisonings among dogs, in countries such as Belgium, Italy, and the Czech Republic (Amorena et al. 2004; Modrá and Svobodová 2009; Vandenbroucke et al. 2010).

The compound is highly toxic when inhaled and moderately toxic when ingested (Gupta 2012). Metaldehyde acts on slugs and snails by ingestion or absorption, irreversibly destroying their mucocytes; unlike in mollusks, metaldehyde acts in humans and carnivores after being absorbed as acetaldehyde from the gastrointestinal tract into the bloodstream (Kamrin 1997). Nevertheless, due to the fact that acetaldehyde was not detected in the urine, brain or plasma of intoxicated animals (Puschner 2001), the mechanism of toxicosis is still questionable. It is thought that the toxicant affects the nervous system by decreasing the $\gamma$-aminobutyric acid, serotonin and norepinephrine concentrations, and increasing the 
activity of monoamine oxidase (Homeida and Cooke 1982; Puschner 2001). As in humans, most of the currently reported metaldehyde toxicosis in dogs followed ingestion. Although concentrations of metaldehyde in domestic products are low, their extensive use as molluskicides, high availability and low price increase the risk of accidental poisonings among domestic carnivores.

Diagnosis of metaldehyde poisoning is based on history of exposure and clinical signs; confirmation of the diagnosis can be made by identifying metaldehyde/acetaldehyde in vomitus or gastrointestinal tract content, blood or urine (Gupta 2012). In our case, diagnosis was established on the basis of the owner's information, who saw the dog ingesting the compound and brought the product's package to the clinic, in correlation with the clinical signs presented upon admission. Furthermore, a bluish green content in the patient's faeces sustained the ingestion of metaldehyde-containing granules. Additional toxicological testing was declined due to the owner's financial limitations.

Seizures and muscle tremors were the most prominent clinical findings in the current case. Severe toxicity signs that appeared suddenly according to the owner, may have been caused by the consumption of a large amount of toxicant and it can be related to the patient's young age. Similarly, most of the metaldehyde poisoning reports in veterinary literature revealed mainly neurological signs (seizures, muscle tremor, nystagmus), tachycardia, tachypnoea, hyperthermia and less frequently gastrointestinal signs (Yas-Natan et al. 2007; Richardson et al. 2003).

Regarding the biochemical findings upon admission, a previous study showed an increased muscle enzymes activity (Yas-Natan et al. 2007). In agreement with this finding, markedly elevated creatine kinase $(34.83 \mu \mathrm{kat} / \mathrm{l})$ values and moderately increased aspartate aminotransferase $(0.527 \mu \mathrm{kat} / \mathrm{l})$ values were observed in this case, presumably due to severe generalized tonic-clonic activity. A mild hyperglycaemia was noticed, probably due to the altered glycaemic metabolism and/or severe state of shock.

Since no specific antidote is known, symptomatic treatment and fluid therapy are the main recommendations. Diazepam, pentobarbital, methocarbamol, propofol or sodium phenobarbital are some of the substances described to be effective in metaldehyde-induced seizures and muscle tremor management (Richardson et al. 2003; Yas-Natan et al. 2007; Gupta 2012). In this case, no significant improvements in the CNS (central nervous system) signs were seen after diazepam, phenobarbital and propofol administration.

Intravenous lipid emulsion therapy represents a novel and promising method used for treating toxicity of lipophilic compounds, including baclofen, ivermectin, calcium channel blockers, etc. (Rothschild et al. 2010; Loftin 2012). It hypothetically acts by creating an intravascular lipid phase in which the lipophilic injurious compound is drawn from the target tissues (Roth schild et al. 2010). No studies regarding the use of ILE in metaldehyde toxicosis in dogs were described in the literature at the time of treatment and, therefore, no information about the recommended dosage were known.

Because metaldehyde is described as being a lipid-soluble toxin (Allen et al. 2004; Loftin 2012), we assumed that ILE therapy should be able to reduce toxin tissue concentrations, leading to a significant improvement in the clinical signs. Intravenous lipid emulsion therapy is adapted from human medicine protocols, due to lack of reports in veterinary medicine regarding metaldehyde poisoning. General recommendations in intoxications suggest an initial bolus between 1.5 and $4 \mathrm{ml} / \mathrm{kg}$ over $1-15 \mathrm{~min}$, followed by a CRI at $0.25 \mathrm{ml} / \mathrm{kg} / \mathrm{min}$, for 30-120 $\mathrm{min}$ (Loftin 2012; Fernandez et al. 2011). In our case, a total dose of $19 \mathrm{ml} / \mathrm{kg} /$ day was administered, which was followed by a remarkable improvement of the tonic-clonic activity and complete resolution of the clinical signs.

The current case report describes a canine patient with severe CNS signs following metaldehyde poisoning, that was successfully treated by using ILE therapy without subsequent complications. 
To the authors' knowledge, this is the first report describing ILE in the treatment of metaldehyde intoxication in dogs. As only a single dog was subjected to the presented therapy, the authors acknowledge its limited extent. Considering the patient's rapid improvement, the authors look forward for future research regarding the extended use and appropriate dosage of ILE in metaldehyde poisonings for a safe therapeutic approach.

\section{References}

Allen D, Dowling PM, Smith DA, Pasloske K, Woods JP 2004: Handbook of veterinary drugs. ${ }^{\text {rd }}$ ed. Lippincott Williams \& Wilkins, Philadelphia, $300 \mathrm{p}$

Amorena M, Caloni F, Mengozzi G 2004: Epidemiology of intoxications in Italy. Vet Res Commun 28: 89-95

Beasley VR 1999: Toxicants associated with CNS stimulation or seizures. A Systems Affected Approach to Veterinary Toxicology. University of Illinois College of Veterinary Medicine, Urbana, pp. 94-97

Booze TF, Oehme FW 1985: Metaldehyde toxicity: A review. Vet Hum Toxicol 27: 11-19

Fernandez AL, Lee JA, Rahilly L, Hovda L, Brutlag AG, Engebretsen K 2011: The use of intravenous lipid emulsion as an antidote in veterinary toxicology. J Vet Emerg Crit Care 21: 309-320

Gupta R 2012: Metaldehyde. In: Veterinary Toxicology: Basic and Clinical Principles. $2^{\text {nd }}$ ed. Academic Press, Oxford, pp 518-520

Homeida AM, Cooke RG 1982: Pharmacological aspects of metaldehyde poisoning in mice. J Vet Pharmacol Ther 5: 77-81

Kamrin MA 1997: Pesticide profiles: toxicity, environmental impact and fate. CRC Press, New York, 565 p.

Loftin E 2012: Toxicities in the ER. In: DoveLewis Annual Conference: Portland, Oregon, pp 2-3

Modrá H, Svobodová Z 2009: Incidence of animal poisoning cases in the Czech Republic: current situation. Interdiscip Toxicol 2: 48-51

Puschner B 2001: Metaldehyde. In: Small Animal Toxicology (Peterson ME, Talcott PA, eds). Saunders WB, Philadelphia, pp. 553-562

Richardson JA, Welch SL, Gwaltney-Brant SM, Huffman JD, Rosendale ME 2003: Metaldehyde toxicoses in dogs. Comp Cont Educ Pract 25: 376-380

Rothschild L, Bern S, Oswald S, Weinberg G 2010: Intravenous lipid emulsion in clinical toxicology. Scand J Trauma Resusc Emerg Med 18: 51

Vandenbroucke V, Van Pelt H, De Backer P, Croubels S 2010: Animal poisonings in Belgium: a review of the past decade. Vlaams Diergeneeskd Tijdschr 79: 259-268

Yas-Natan E, Segev G, Aroch I 2007: Clinical, neurological and clinicopathological signs, treatment and outcome of metaldehyde intoxication in 18 dogs. J Small Anim Pract 48: 438-443 